\title{
Low-dose trofosfamide plus rituximab is an effective and safe treatment for diffuse large B-cell lymphoma of the elderly: a single center experience
}

\author{
Roland Christian Schelker ${ }^{*}$ (D, Wolfgang Herr, Albrecht Reichle and Martin Vogelhuber
}

\begin{abstract}
Background: Rituximab plus combination chemotherapy with cyclophosphamide, doxorubicin, vincristine, and prednisone (R-CHOP) is broadly accepted as standard for the treatment of diffuse large B-cell lymphoma (DLBCL). Nevertheless, there is sparsely data concerning the management of elderly patients.

Methods: We performed a retrospective study of treatment with rituximab and low-dose trofosfamide in elderly patients ( $\geq 75$ years) with DLBCL who were not suitable for R-CHOP or R-CHOP-like regimens or who did not consent to aggressive treatment. The choice regarding the qualification for R-CHOP or R-CHOP-like regimen was left to the estimation of the treating physicians.

Results: Eleven patients with a median age of 83 years (range, 75-90 years) were included. The age-adjusted international prognostic index was low risk in one patient, low-intermediate in four patients, high-intermediate in three patients, and high risk in 3 patients. All patients were evaluable for response. Five patients (45\%) achieved a complete response, three (27\%) a partial response, one (9\%) stable disease, and two (18\%) progressive disease. The estimated 1-yr overall survival was $54.5 \%$, and the estimated 1-yr progression-free survival $45.5 \%$, however, three patients (27\%) were alive without evidence of disease at 16-20 months from start of treatment. Main toxicity was leukopenia (36\% grade III or IV), whereas grade III/IV non-hematological adverse events did not occur.

Conclusions: Due to its potency and low toxicity, trofosfamide/rituximab might represent an alternative therapy for DLBCL of elderly patients not suitable for R-CHOP. This observation, however, should be confirmed in a larger patient population within a prospective clinical trial.
\end{abstract}

Keywords: Diffuse large B-cell lymphoma, Rituximab, Trofosfamide, Elderly patients

\section{Background}

Diffuse large B-cell lymphoma (DLBCL) is by far the most common subtype of high-grade B-cell non-Hodgkin lymphoma (B-NHL) in adults. Worldwide, the current annual incidence of DLBCL is estimated to be 7 cases per 100,000 persons [1]. This incidence continually increases with age, and approximately $40 \%$ of cases occur in patients elder than 70 years [2]. Due to the global ascent of the older population, an additional rise of the absolute count

\footnotetext{
* Correspondence: roland.schelker@ukr.de

Department of Internal Medicine III, Hematology \& Oncology, University Hospital Regensburg, Franz-Josef-Strauss-Allee 11, 93053 Regensburg, Germany
}

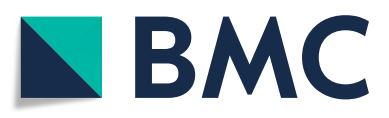

(c) The Author(s). 2018 Open Access This article is distributed under the terms of the Creative Commons Attribution 4.0 International License (http://creativecommons.org/licenses/by/4.0/), which permits unrestricted use, distribution, and reproduction in any medium, provided you give appropriate credit to the original author(s) and the source, provide a link to the Creative Commons license, and indicate if changes were made. The Creative Commons Public Domain Dedication waiver (http://creativecommons.org/publicdomain/zero/1.0/) applies to the data made available in this article, unless otherwise stated. old people. Retrospective data have already delineated that the prognosis of elderly patients is worse than that of younger patients, the choice of adequate treatment modalities being a real challenge [3-6].

It is not clear if DLBCL in the elderly carries a different genotype than in younger patients but it was demonstrated that molecular features with distinct prognosis are associated with age [7]. Nevertheless, DLBCL in elderly patients is not considerably less responsive to treatment than in younger patients, and the principal reason for the poor prognosis of very old patients is their diminished ability to tolerate treatment [8]. The number of treatment-related 
adverse events is heightened by limited bone-marrow function, altered drug metabolism, and existence of comorbid diseases. Various efforts to reduce doses of the standard chemotherapy regimen CHOP (cyclophosphamide, doxorubicin, vincristine, and prednisone) or to replace the components with less toxic drugs have diminished toxicity but did not ameliorate survival [9-11].

The major therapeutic advancement made by incorporation of the monoclonal antibody rituximab with $\mathrm{CHOP}$ (R-CHOP) has modified the treatment outcome of patients with DLBCL dramatically. A randomized open-label trial by the Groupe d'Etudes des Lymphomes de l'Adulte (GELA) in patients aged 60-80 years showed significantly superior complete response and survival rates in patients treated with $\mathrm{CHOP}$ and Rituximab compared to $\mathrm{CHOP}$ alone, without a clinically increase in toxicity [12-14]. These results were reproduced by two randomized trials in a similar patient population $[15,16]$.

Since then, incorporation of rituximab in R-CHOP-like regimens has been examined for more frail elderly patients in several phase II trials [17-26], demonstrating efficacy and tolerability. Nevertheless, the rate of circumstances incapacitating patients from $\mathrm{R}-\mathrm{CHOP}$-like regimens is elevated in elderly population. Hence, alternative efficient treatment options with less toxicity are needed. Such treatments, accompanied by supportive measures and frequent toxicity monitoring, can be more than palliative and add considerable quality/quantity of life.

In the pre-rituximab era, the findings of phase II studies with metronomic low-dose trofosfamide (50 to150 mg/ day) in patients with relapsed or refractory NHL, who did have a palliative treatment option, were published, but these studies revealed only an overall response rate (ORR) of $50 \%$ and median response duration of 4 months in a small cohort of NHL patients, including DLBCL [27-30]. Few long-term complete remissions (7-10 months) were observed, even in patients with refractory disease [29]. Toxicity was generally mild despite bone marrow depression with leukopenia up to grade III. In one particular case of relapsing anaplastic large-cell lymphoma trofosfamide treatment resulted in ongoing complete remission 16 months after withdrawal of the drug [31]. Since these findings proved potency of trofosfamide in NHL and as the drug was very well-tolerated yet in older patients [32], compassionate use of low-dose trofosfamide and rituximab (R-T) in elderly patients who were not eligible for standard immunochemotherapy, was conducted. Notably, rituximab is approved for first-line treatment of CD20 $0^{+} \mathrm{NHL}$ worldwide, while trofosfamide is approved in Germany for treatment of NHL after failure of standard chemotherapy.

Trofosfamide is an alkylating agent of the group of oxazaphosphorines [33]. A number of preclinical and clinical findings showed that pharamacodynamics and the mode of action of the medication considerable vary from classical alkylating agents like cyclophosphamide, which is part of the CHOP regimen. Contrary to the other oxazaphosphorines, trofosfamide is more lipophilic and is only disposable as an oral formulation [34]. In vitro examination revealed crosslinks between DNA and chromosomal proteins and showed some antiangiogenetic potential in the metronomic schedule [35, 36]. Trofosfamide is a prodrug, known to be metabolized mainly to ifosfamide and merely to a small rate to cyclophosphamide [37]. Recently, Brinker et al. revealed a third pathway in the metabolism of trofosfamide to 4-hydroxy-trofosfamide, which seems to be the most important one [34].

Trofosfamide has evinced a wide efficacy in the therapy of multitudinous hematological and solid tumors [38]. Currently, there is no randomized trial to compare trofosfamide with standard therapy. Moreover, thus far no data exist, associating rituximab to trofosfamide treatment.

Therefore, we here present the first study that investigates trofosfamide in combination with rituximab for the treatment of patients with DLBCL and also the first report on trofosfamide given as first-line therapy in this disease entity.

\section{Methods}

\section{Patients}

In this study, we conducted a retrospective investigation of 11 cases diagnosed with DLBCL who were treated in first-line $(n=4)$, second-line $(n=6)$ and third-line (1) therapy with $\mathrm{R}-\mathrm{T}$ chemoimmunotherapy at University Hospital Regensburg. Medical files of cases trailed between March 2014 and June 2017 were examined. Informed consent was obtained from each patient that drugs, approved for lymphoma therapy should be used, which have not been tested in combination, yet.

In every patient, histological evaluation and appropriate immunophenotyping assays were conducted on tissue specimen recieved from lymph node extirpations and resections of extranodal manifestation sites including endoscopic biopsies and bone marrow (BM) biopsies, and diagnosis was made conformable to the World Health Organization (WHO) classification for malignancies of lymphoid origin [39].

The following clinical and histological information was compiled: age, symptoms, performance status (PS), clinical stage, extent of extranodal, nodal and BM involvement, lactate dehydrogenase (LDH), International Prognostic Index (IPI), proliferation index, prior treatment, status before rituximab/trofosfamide, and treatment duration in months. The IPI score was documented agreeable to the established system [40]. The staging was performed according to the Ann Arbor staging criteria [41].

In all cases, appropriate clinical assessment before R-T immunochemotherapy, during therapy in intervals of 3 weeks (one cycle), at progression, withdrawal of 
consent, severe side effects, every month after achieving $\mathrm{CR}$ and during post-treatment follow-up (every 3 months) was performed. Before starting therapy, the evaluation comprised at least a physical investigation, hematological and chemical laboratory examination and positron emission tomography-computed tomography (PET-CT) [or contrast-enhanced computed tomography (CT) of chest, abdomen and pelvis]. Supplementary BM biopsy was done in cases with BM infiltration to evaluate the efficacy of the therapy. In follow-up clinical and laboratory assessment was performed before start of the next cycle. Response was assessed after every 2 cycles ( 3 weeks/cycle) of therapy and after stop of therapy of any cause in line with the 2007 International Working Group revised response criteria [42]. Patients were categorized conformable to most favorable regress: complete response (CR), partial response (PR), stable disease (SD), or disease progression (PD). The ORR was defined as the population who acquired a CR or PR, respectively. Toxicities were recorded and were ranking according to the Common Toxicity Criteria for Adverse Events v3.0 [43].

The R-T treatment comprised rituximab (MabThera ${ }^{\circ}$, Roche Germany) administered at $375 \mathrm{mg} / \mathrm{m}^{2}$ intravenously (at first administration) and $1400 \mathrm{mg}$ subcutaneously (subsequent administrations) on day 1 of every cycle and trofosfamide (Ixoten ${ }^{\circ}$ Baxter Oncology Germany) given at a metronomic (low) dose of $50 \mathrm{mg}$ (1 patient), $100 \mathrm{mg}$ (8 patients; two single doses of $50 \mathrm{mg}$ ) or $150 \mathrm{mg}$ (two patients; three single doses of $50 \mathrm{mg}$ ) daily by oral administration on day $1-21$. In the two patients who started with trofosfamide $150 \mathrm{mg}$ daily, dose adaption to $100 \mathrm{mg}$ daily was necessary due to cytopenia during the course of treatment. Prior to the application of rituximab, premedication with $4 \mathrm{mg}$ dimetindene was administered intravenously. Rituximab was given in 21-day cycles up to 8 cycles, trofosfamide until PD, cytopenia or impaired PS and 10 cycles after achieving CR. Rituximab was given in the out-patient clinic. The median treatment duration was 5 months. Granulocyte-colony-stimulating factor (G-CSF) was not administered.

The retrospective patient analysis was performed in accordance with the current version of the Helsinki Declaration and the use of oral consent had been approved by the local Ethics Committee of Human Experimentation, University Regensburg, documented by the notification with the reference number: 17-667-104. All cases were anonymized and their medical files were investigated anonymously. Informed consent for publication of anonymized medical files for research purpose was received orally from every patient.

\section{Statistical analysis}

Analyses were performed using PRISM 7 (Graphpad, San Diego, CA, US) statistical software. Patient features are showed as descriptive statistics, with numbers for categorical variables. Kaplan-Meier survival evaluation was conducted appreciate the progression-free survival (PFS) and overall survival (OS). PFS was monitorized from starting R-T treatment to $\mathrm{PD} /$ relapse or death. Length of follow-up was calculated from the moment of beginning $\mathrm{R}$-T treatment to the final follow-up or time of death.

\section{Results}

\section{Patient characteristics}

We conducted an electronically quest in the catalogue of the University Hospital Regensburg. Altogether 11 cases with histologically-evidenced DLBCL treated with R-T from February 2014 to June 2016 were perceived. Patients were registered successively with the intention to prevent selection bias.

Table 1 recapitulates the patient features at diagnosis, prior treatment regimen and the status at first application of R-T. The median age at treatment onset was 83 (range 75 to 90 ) years. At the beginning of the investigation, 55\% had a favorable (ECOG $0-1$ ) and $45 \%$ a compromised (ECOG 2-3) PS. LDH was elevated in 27\% of the patients. Conformable to Ann Arbor criteria, 18\% were staged as stage I, $18 \%$ as stage II, $18 \%$ as stage III and $45 \%$ as stage IV. In all but three of the patients extranodal manifestations and associated clinical symptoms could be identified. Thereof, 63\% presented with extra-lymphatic manifestations including the left thoracic wall, the gluteal muscles, the left kidney and the left adrenal gland, both mammary glands, the spleen, the liver, the bones inclusively the BM, cerebral and meningeal dissemination and cutaneous infiltration. According to IPI, 9\% were at low risk, 36\% were at low-intermediate risk, $27 \%$ at high-intermediate risk and $27 \%$ at high risk. Expression of CD20 in lymphoma tissue could be detected in all patients by immunohistochemical analyses, while only 9\% expressed CD5, 55\% CD10, 9\% CD30, 18\% CD79a, 9\% CD138, 82\% BCL2, 55\% BCL6 and $36 \%$ MUM1. Median proliferation index Ki-67 or MiB1was $83 \%$, ranging from 40 to $95 \%$.

\section{Treatment}

All 11 patients obtained R-T therapy as scheduled. In consensus with our institutional guideline the indication for this immunochemotherapy regimen was as follows: First-line treatment was indicated in patients being not eligible for $\mathrm{R}-\mathrm{CHOP}$ or R-CHOP-like regimens due to multiple comorbidities, poor PS or higher age; rescue treatment with R-T was indicated in patients with PD or relapse after R-CHOP or R-CHOP-like regimens. Some patients (27\%) were extensively pretreated: 5 cycles of B-ALL/NHL regimen of the German ALL study group [44] (rituximab, cyclophosphamide, methotrexate, vindesine, etoposide, doxorubicin, cytarabine); 6 cycles of R-mini-CHOP [21] + 6 cycles R-TPIP (rituximab, trofosfamide, procarbazine, 
Table 1 Patients characteristics

\begin{tabular}{|c|c|c|c|c|c|c|}
\hline ID & stage & $\mathrm{IPI}$ risk & PS & extranodal involvement & immunohistochemical expression & $\begin{array}{l}\mathrm{LDH} \text { at diagnosis in } \mathrm{U} / \mathrm{I} \\
(\text { Normal }<250 \mathrm{U} / \mathrm{l})\end{array}$ \\
\hline 1 & $\|$ & low & 1 & oropharynx, base of the tongue & CD5, CD10, CD20, BCL2 & 122 \\
\hline 2 & III & high & 1 & $\mathrm{~N}$ & CD10, CD20, CD30, BCL2, BCL6 & 369 \\
\hline 3 & $\|$ & high-intermediate & 3 & $\mathrm{~N}$ & CD20, BCL2, BCL6, MUM1 & 718 \\
\hline 4 & 1 & low-intermediate & 2 & stomach & CD10, CD20, BCL6 & 184 \\
\hline 5 & IV & high & 1 & $\begin{array}{l}\text { left thoracic wall, gluteal muscles, } \\
\text { left kidney, spleen, liver }\end{array}$ & CD10, CD20, BCL2, BCL6, MUM1 & 312 \\
\hline 6 & III & high-intermediate & 2 & bone marrow & CD20, CD79a, BCL2, BCL6, MUM1 & 180 \\
\hline 7 & IV & high-intermediate & 2 & $\begin{array}{l}\text { os ileum, left sacroiliac joint, lumbar } \\
\text { vertrebal body } 5 \text {, brain }\end{array}$ & CD10, CD20, CD79a, CD138, BCL2 & 196 \\
\hline 8 & IV & high & 2 & skin, meninges, bone marrow & CD20, BCL2 & 164 \\
\hline 9 & । & low-intermediate & 0 & $\begin{array}{l}\text { both mammary glands, left adrenal } \\
\text { gland }\end{array}$ & CD20, CD79a, BCL2, MUM1 & 150 \\
\hline 10 & IV & low-intermediate & 1 & $\mathrm{~N}$ & CD20, BCL2 & 205 \\
\hline 11 & I & low-intermediate & 1 & right tonsill & CD10, CD20, BCL6 & 209 \\
\hline
\end{tabular}

IPI International Prognostic Index, PS performance status, $N$ negative, $C D$ cluster of differentiation, $B C L$ B-cell lymphoma, $M U M$ multiple myeloma oncogene, $L D H$ lactate dehydrogenase

idarubicin, prednisone); 6 cycles $\mathrm{R}-\mathrm{CHOP}+14 \times$ rituximab maintenance. Moreover, in single patients pre-treatment with cyclophosphamide $(n=2)$ or one cycle R-HOP $(n=1)$ was performed prior to R-T due to bulky disease.

\section{Response and follow-up}

The response data is specified in Table 2. The ORR was $73 \%$ with 5 CR and 3 PR. One patient developed SD and the remaining two patients had PD. Among the patients who achieved CR, $40 \%$ presented complete disappearance of lymphoma after 6 cycles, whereas the other $60 \%$ developed CR after 8 cycles of R-T therapy. It is noteworthy that in $45 \%$ of the patients the incipient symptoms completely disappeared, while $36 \%$ showed a reduction of symptoms and the patients who presented PD did not improve at all.

Of the 5 patients who achieved CR, $60 \%$ could maintain this status even long time after cessation of treatment (714 months after discontinuation of R-T), the remaining $40 \%$ endured cerebral PD 1-3 month after attaining CR. Of the patients who developed PR 67\% progressed with extranodal PD (enoral, ileum) after 3-8 months of continuous R-T treatment, 33\% remained in stable PR for 6 months. One patient had SD without cessation of therapy. Two cases had PD at the first staging after 2 months on R-T. At a median observation time of 12 months, 73\% of the patients were alive, and $27 \%$ were in sustained CR. The estimated PFS at 1 year was $45.5 \%$ with an estimated median duration of 9.4 months (Fig. 1a). The estimated 1-yr overall survival (OS) was $54.5 \%$ (Fig. 1b). Six patients survived longer than 12 months, with only one of them dying 20 months after beginning R-T therapy due to PD. A subgroup analysis of our data (Fig. 2a, b, c and d) suggested that a benefit from treatment with R-T not alone occurred in cases with limited stages or low IPI, but also in three patients with stage IV and two patients with high-risk/one with intermediate-high risk corresponding to IPI who were alive in $\mathrm{CR}(n=2)$ or $\mathrm{SD}(n=1)$ 16 months or longer after treatment was started.

\section{Toxicity}

Median time on therapy was 5 months. Therapy-associated toxicities were smooth and endurable (Table 2). Hematologic toxicities were basically noticed, with leukopenia grade III and IV in 36\% of the patients. After interruption of therapy, hematology was followed weekly, and treatment with trofosfamide restarted at one dose

Table 2 Response and side effects

\begin{tabular}{llll}
\hline ID & response & \multicolumn{2}{l}{ grade III/IV side effects } \\
\cline { 3 - 4 } & & hematologic & non-hematologic \\
\hline 1 & PR & no & no \\
2 & PR & pancytopenia & no \\
3 & CR & leukopenia & no \\
4 & CR & no & no \\
5 & CR & pancytopenia & no \\
6 & CR & no & no \\
7 & SD & no & no \\
8 & CR & leukopenia & no \\
9 & PD & no & no \\
10 & PR & no & no \\
11 & PD & no & no \\
\hline$P R$ partial response, $C R$ complete response, SD stable disease, $P D$ \\
progressive disease
\end{tabular}



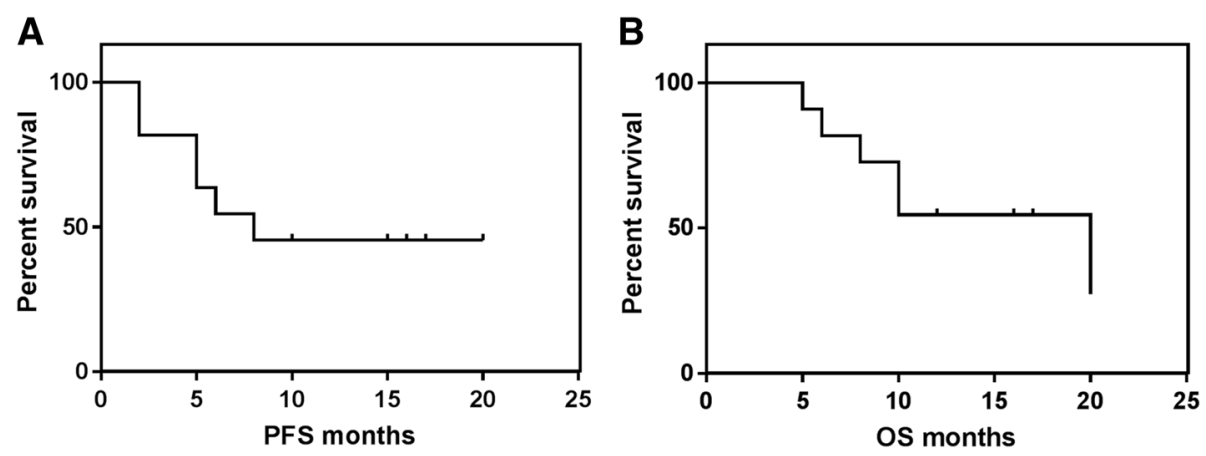

Fig. 1 a Kaplan-Meier curves on progression-free survival (PFS) and (b) overall survival (OS) for patients $(n=11)$ who were treated with the R-T regimen

level lower (reduction of $50 \mathrm{mg}$ daily) when leukopenia had resolved to $\leq$ Grade II. In all cases leukopenia resolved within 3 weeks. Grade I nausea and dyspnea was observed in $9 \%$ during administration of rituximab, grade I fatigue and anorexia in other 9\% during R-T therapy. One patient reported cramps in the leg. No incident of febrile neutropenia resulting in hospitalization occurred.

\section{Discussion}

Our retrospective clinical study suggests that the R-T regimen is effective and well-tolerated in DLBCL of elderly and comorbid patients, and additionally, as three of the cases are still alive in the absence of lymphoma 16, 17 and 20 months upon treatment, respectively, they suggest that the treatment could be even curative in a fraction of patients with ongoing $\mathrm{CR}$. The survey was not planned to substitute the latest standard, R-CHOP, in older patients [45], nor should it replace R-CHOP-like regimens: nonpegylated liposomal doxorubicin instead of standard doxorubicin (R-COMP) [17, 18]; combination of rituximab and nonpegylated liposomal doxorubicin (R-NPLD) [19]; replacement of conventional doxorubicin by pegylated liposomal doxorubicin [20]; R-mini-CHOP [21]; a dose-adjusted infusional regime (DA-POCH-R) [22]; induction R-CNOP or R-CVP for three cycles, followed by maintenance rituximab in responders [23]; substitution of gemcitabine for anthracycline in a $\mathrm{R}$-CHOP-like regimen (R-GCVB) [24]; combination of ofatumumab and reduced-dose CHOP [25]; induction $\mathrm{R}-\mathrm{EPOCH}$ or R-CEOP [26]. However, the primary motivation for this
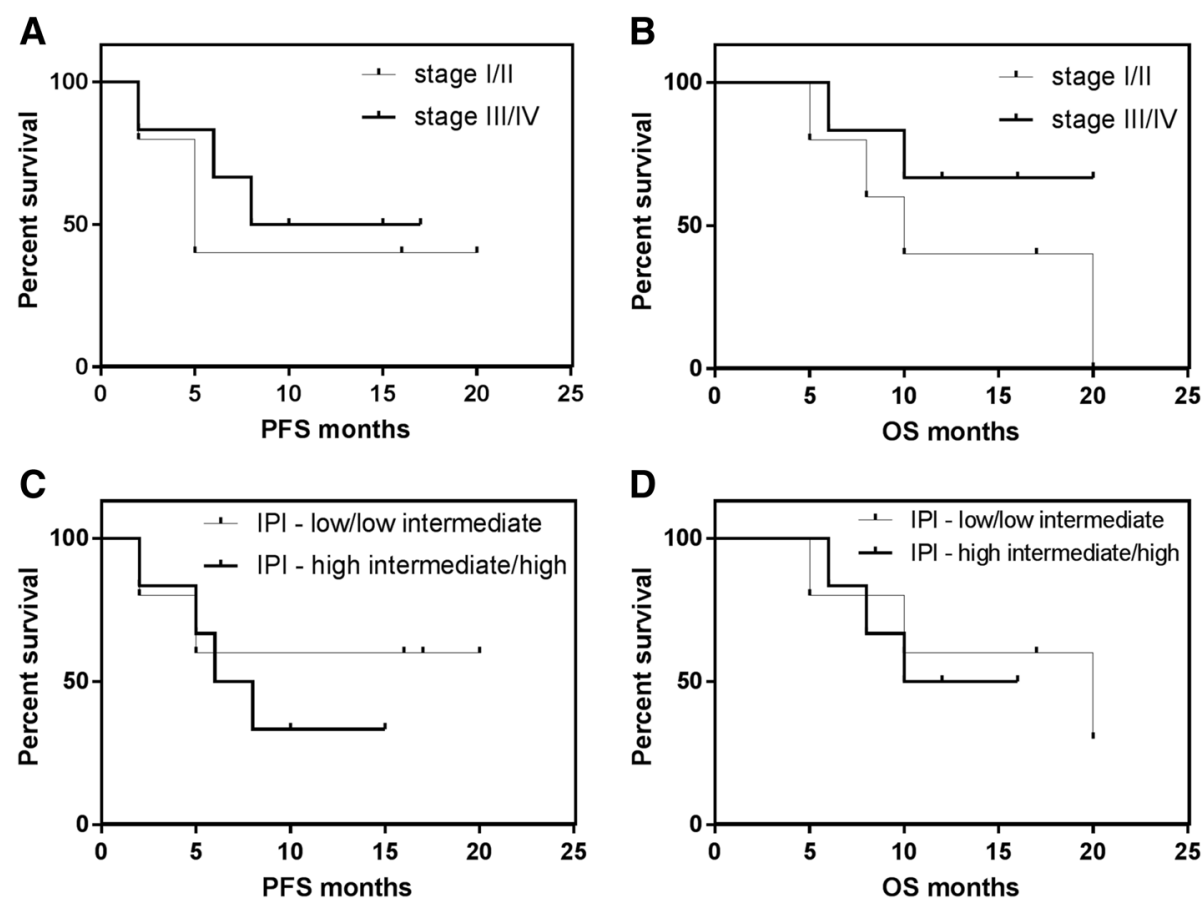

Fig. 2 Kaplan-Meier curves on progression-free survival (PFS) and overall survival (OS) with regard to Ann Arbor staging (a, b) and age-adjusted international prognostic index $(\mathbf{c}, \mathbf{d})$ 
retrospective study has been to define an adequate therapy for patients, who were classified by their hematologists not to be suitable for repetitive R-CHOP or R-CHOP-like regimens. Actually, Thieblemont et al. [5] highlighted in their study of NHL cases elder than 80 years that a treatment choice was frequently difficult. In their study of 205 cases, merely $4 \%$ had obtained standard treatment with $\mathrm{CHOP}$ or R-CHOP. This evaluation shows that in the global population of older patients with highly malignant lymphomas, a significant number is not categorized by their doctors to be eligible for CHOP or R-CHOP and hence, other potentially less toxic combinations are necessary. Nevertheless, for this population, there is a lack of data disposable to direct treatment decision.

The CR proportion of $45 \%$ in the current retrospective data analysis appears inferior than in a group of cases elder than 75 years who received R-CHOP; nevertheless, one must take into consideration that a patient cohort like this follows intense screening and solely patients with a superb PS and few comorbidities will finally undergo therapy with R-CHOP. Regarding R-CHOP-like regimens, the CR rate appears comparable or even better (R-CVP: 37\%; R-GCVB 39\%) [24, 46], and the toxicity profile seems more moderate for R-T. Thus R-T combines both, efficacy and tolerability in comorbid elderly DLBCL patients.

In a prospective phase II study by Park et al. applying a regimen based on bendamustine and rituximab (B-R), a group of 23 patients with a median age of 80 years was examined for efficacy and toxicity. The response rate was similar to our work, with $78 \%$ ORR and $52 \%$ CR. In general, the treatment was excellent tolerated; though, sixteen patients deceased in the course of the study period, four of them treatment-related [47]. These results are comparable to recently published retrospective or prospective studies of B-R in the elderly $[48,49]$. To our knowledge, $\mathrm{B}-\mathrm{R}$ is the only published regimen alternative to $\mathrm{R}-\mathrm{CHOP}$ or R-CHOP-like regimens excepting the findings reported in our study in elderly cases with DLBCL and this scarceness of information emphasizes the necessity for subsequent studies in this age-cohort. Experience with distinct combination therapies and integration of geriatric scores are required to ease the adjudication, in whom a standard procedure could be beneficial and in whom other options could be the more favorable selection.

A subgroup examination of our data suggests that high-risk patients may also benefit from treatment with R-T. However, based on the small number of patients studied, it was not feasible to pick out any factor that would predict cases with beneficial outcome after therapy with R-T. In the study by Thieblemont et al. [5], IPI and Ann Arbor staging were separate prognostic factors in a multivariate analysis. This is presumably also the case for patients treated with R-T; however, our report suggests that R-T could be effective even in a significant population with advanced-stage and/or unfavorable IPI. We would like to emphasize, that $\mathrm{R}-\mathrm{T}$ was effective with trofosfamide even at low dose of 50-100 mg daily.

Taking into account the seniority of our cohort, the toxicity of R-T was quite mild. Compared to the studies with the B-R regimen in DLBCL of the elderly [47, 48], grade III and IV non-hematological adverse events could not be detected. Adverse events were principally hematologic toxicities, with grade III and IV leukopenia in $4 / 11(36 \%)$ patients. In comparison with studies utilizing trofosfamide monotherapy [27-30] in patients with DLBCL, hematologic and non-hematologic toxicity were greatly alike, which confirmed the relatively mild toxicity of this regimen. Notably, the low rate of hematotoxicity in the present report was achieved, although G-CSF was not administered. Furthermore, the R-T combination does not lead to alopecia. Patients with a poor PS were, contrary to the study on the B-R regimen by Weidmann et al. [48], not excluded in our work; these patients could be precisely the subgroup that most probable benefits from R-T since cardiac toxicity is very low, and additionally, the combination is excellent tolerated by older patients as shown in this report.

\section{Conclusions}

In summary, R-T is an effective and well-tolerated treatment regimen and hence should be considered particularly in older and/or comorbid patients with DLBCL who are not suitable candidates for R-CHOP or R-CHOP-like regimens. Nevertheless, the number of patients in this study is low, and therefore, our findings have to be validated in larger study populations. Moreover, the retrospective nature of the study makes the adverse events difficult to interpret and difficult to compare to other regimens. Therefore, future trials should be designed prospectively and comprise geriatric assessment scores which could assist to recognize subgroups of DLBCL patients who will benefit from treatment with R-T.

\footnotetext{
Abbreviations

BM: bone marrow; B-NHL: B-cell non-Hodgkin lymphoma; B-R: bendamustine and rituximab; CHOP: cyclophosphamide, doxorubicin, vincristine, prednisone; CR: complete response; CT: computed tomography; DLBCL: diffuse large B-cell lymphoma; G-CSF: granulocyte-colony-stimulating factor; GELA: Groupe d'Etudes des Lymphomes de l'Adulte; IPI: International Prognostic Index; LDH: lactate dehydrogenase; ORR: overall response rate; OS: overall survival; PD: disease progression; PET-CT: positron emission tomography-computed tomography; PFS: progression-free survival; PR: partial response; PS: performance status; R-CHOP: rituximab with $\mathrm{CHOP}$; RNPLD: rituximab with nonpegylated liposomal doxorubicin; R-T: rituximab and trofosfamide; R-TPIP: rituximab, trofosfamide, procarbazine, idarubicin, prednisone; SD: stable disease; WHO: World Health Organization
}

Availability of data and materials

The datasets used and/or analysed during the current study are available from the corresponding author on reasonable request. 


\section{Authors' contributions}

RS contributed to the following items: conceptualization, methodology, validation, formal analysis, investigation, resources, data curation, writing original draft, writing-review and editing, visualization, project administration; WH contributed to the following items: methodology, validation, writingreview and editing, visualization, supervision; AR contributed to the following items: conceptualization, methodology, validation, writing-review and editing, visualization, supervision; MV contributed to the following items: conceptualization, methodology, validation, writing-review and editing, visualization, supervision, project administration. All authors read and approved the final manuscript.

\section{Ethics approval and consent to participate}

The retrospective patient analysis is in accordance with the current version of the Helsinki Declaration and is approved by the local Ethics Committee of Human Experimentation, University Regensburg (reference number: 17-667-104). Informed consent was obtained written from each patient that drugs, approved for lymphoma therapy should be used, which have not been tested in combination, yet.

\section{Consent for publication}

Not applicable.

\section{Competing interests}

The authors declare that they have no competing interests.

\section{Publisher's Note}

Springer Nature remains neutral with regard to jurisdictional claims in published maps and institutional affiliations.

Received: 18 September 2017 Accepted: 1 October 2018

Published online: 19 October 2018

\section{References}

1. Morton LM, Wang SS, Devesa SS, Hartge P, Weisenburger DD, Linet MS. Lymphoma incidence patterns by WHO subtype in the United States, 19922001. Blood. 2006;107:265-76.

2. d'Amore F, Brincker $H$, Christensen BE, Thorling $K$, Pedersen M, Nielsen JL, et al. Non-Hodgkin's lymphoma in the elderly. A study of 602 patients aged 70 or older from a Danish population-based registry. The Danish LYEO-Study Group. Ann Oncol. 1992;3(5):379-86.

3. Hoerni B, Sotto JJ, Eghbali H, Sotto MF, Noerni-Simon G, Pegourié B. NonHodgkin's malignant lymphomas in patients older than 80: 70 cases. Cancer. 1988;61:2057-9.

4. Bairey O, Benjamini O, Blickstein D, Elis A, Ruchlemer R. Non-Hodgkin's lymphoma in patients 80 years of age or older. Ann Oncol. 2006;17:928-34.

5. Thieblemont C, Grossoeuvre A, Houot R, Broussais-Guillaumont F, Salles G, Traullé C, et al. Non-Hodgkin's lymphoma in very elderly patients over 80 years. A descriptive analysis of clinical presentation and outcome. Ann Oncol. 2008;19:774-9.

6. Italiano A, Jardin F, Peyrade F, Saudes L, Tilly H, Thyss A. Adapted CHOP plus rituximab in non-Hodgkin's lymphoma in patients over 80 years old. Haematologica. 2005;90:1281-3.

7. Klapper W, Kreuz M, Kohler CW, Burkhardt B, Szczepanowski M, Salaverria I, et al. Patient age at diagnosis is associated with the molecular characteristics of diffuse large B-cell lymphoma. Blood. 2012;119:1882-7.

8. Armitage JO, Potter JF. Aggressive chemotherapy for diffuse histiocytic lymphoma in the elderly: increased complications with advancing age. J Am Geriatr Scc. 1984;32:269-73.

9. Bastion Y, Blay JY, Divine M, Brice P, Bordessoule D, Sebban C, et al. Elderly patients with aggressive non-Hodgkin's lymphoma: disease presentation, response to treatment, and survival - a group d'étude des Lymphomes de I'Adulte study on 453 patients older than 69 years. J Clin Oncol. 1997;15: 2945-53.

10. Bessell EM, Burton A, Haynes AP, Glaholm J, Child JA, Cullen MH, et al. A randomized multicenter trial of modified $\mathrm{CHOP}$ versus MCOP in patients aged 65 years and over with aggressive non-Hodgkin's lymphoma. Ann Oncol. 2003;14:258-67.

11. Osby E, Hagberg H, Kvaloy S, Teerenhovi L, Anderson H, Cavallin-Stahl E, et al. CHOP is superior to CNOP in elderly patients with aggressive lymphoma while outcome is unaffected by filgrastim treatment: results of a Nordic lymphoma group randomized trial. Blood. 2003;101:3840-8.

12. Coiffier B, Lepage E, Briere J, Herbrecht R, Tilly H, Bouabdallah R, et al. CHOP chemotherapy plus rituximab compared with CHOP alone in elderly patients with diffuse large-B-cell lymphoma. N Engl J Med. 2002;346:235-42.

13. Feugier $P$, Van Hoof $A$, Sebban $C$, Dolal-Celigny $P$, Bouabdallah $R$, Fermé $C$, et al. Long-term results of the R-CHOP study in the treatment of elderly patients with diffuse large B-cell lymphoma: a study by the Groupe d'Etude des Lymphomes de l'Adulte. J Clin Oncol. 2005;23(18):4117-26.

14. Coiffier B, Thieblemont C, van den Neste E, Lepeu G, Plantier I, Castaigne S, et al. Long-term outcome of patients in the LNH-98.5 trial, the first randomized study comparing rituximab-CHOP to standard $\mathrm{CHOP}$ chemotherapy in DLBCL patients: a study by the Groupe d'Etudes des Lymphomes de l'Adulte. Blood. 2010;116:2040-5.

15. Pfreundschuh $M$, Schubert J, Ziepert M, Schmits R, Mohren M, Lengfelder $E$, et al. Six versus eight cycles of bi-weekly CHOP-14 with or without rituximab in elderly patients with aggressive CD20+ B-cell lymphomas: a 17onrandomi controlled trial (RICOVER-60). Lancet Oncol. 2008;9:105-16.

16. Habermann TM, Weller EA, Morrison VA, Gascoyne RD, Cassileth PA, Cohn JB, et al. Rituximab-CHOP versus $\mathrm{CHOP}$ alone or with maintenance rituximab in older patients with diffuse large B-cell lymphoma. J Clin Oncol. 2006;24:3121-7.

17. Visani G, Ferrara F, Alesiani F, Ronconi S, Catarini M, D'adamo F, et al. RCOMP 21 for frail elderly patients with aggressive B-cell non-Hodgkin lymphoma: a pilot study. Leuk Lymphoma. 2008;49:1081-6.

18. Corazzelli G, Frigeri F, Arcamone M, Lucania A, Rosariavilla M, Morelli E, et al. Biweekly rituximab, cyclophosphamide, vincristine, non-pegylated liposomeencapsulated doxorubicin and prednisone (R-COMP-14) in elderly patients with poor-risk diffuse large B-cell lymphoma and moderate to high 'life threat' impact cardiopathy. Brit J Haematol. 2011;154:579-89.

19. Ricciuti G, Finolezzi e LS, Ranucci E, Federico M, Di Nicola M, et al. Combination of rituximab and nonpegylated liposomal doxorubicin (RNPLD) as front-line therapy for aggressive non-Hodgkin lymphoma (NHL) in patients 80 years of age or older: a single-center retrospective study. Hematol Oncol. 2017. https://doi.org/10.1002/hon.2386.

20. Zhou D, Li L, Bao C, Zhu J, Zhu L, Yang X, et al. Replacement of conventional doxorubicin by pegylated liposomal doxorubicin in standard RCHOP chemotherapy for elderly diffuse large B-cell lymphoma: a retrospective study in China. Int J Clin Exp Med. 2015;8(12):22497-502.

21. Peyrade F, Jardin F, Thieblemont C, Thyss A, Emile JF, Castaigne S, et al. Attenuated immunochemotherapy regimen (R-miniCHOP) in elderly patients older than 80 years with diffuse large B-cell lymphoma: a 18onrandomiz, single-arm, phase 2 trial. Lancet Oncol. 2011;12:460-8.

22. Musolino A, Boggiani D, Panebianco M, Fontana E, Zanoni D, Bozzetti C, et al. Activity and safety of dose-adjusted infusional cyclophosphamide, doxorubicin, vincristine, and prednisone chemotherapy with rituximab in very elderly patients with poor-prognostic untreated diffuse large B-cell non-Hodgkin lymphoma. Cancer. 2011;117:964-73.

23. Hainsworth JD, Flinn IW, Spigel DR, Clark BL, Griner PL, Vazquez ER, et al. Brief-duration rituximab/chemotherapy followed by maintenance rituximab in patients with diffuse large B-cell lymphoma who are poor candidates for R-CHOP chemotherapy: a phase II trial of the Sarah Cannon oncology research consortium. Clin Lymph Myel Leuk. 2010;10:44-50.

24. Fields FA, Townsend W, Webb A, Counsell N, Pocock C, Smith P, et al. De novo treatment of diffuse large B-cell lymphoma with rituximab, cyclophosphamide, vincristine, gemcitabine, and prednisolone in patients with cardiac comorbidity: a United Kingdom National Cancer Research Institute project. J Clin Oncol. 2014;32:282-7.

25. Peyrade F, Bologna S, Delwail V, Emile JF, Pascal L, Fermé C, et al. Combination of ofatumumab and reduced-dose $\mathrm{CHOP}$ for diffuse large Bcell lymphomas in patients aged 80 years or older: an open-label, multicenter, single-arm, phase 2 trial from the LYSA group. Lancet Haematol. 2017:4(1):e46-55.

26. Chihara D, Westin JR, Oki Y, Ahmed MA, Do B, Fayad LE, et al. Management strategies and outcomes for very elderly patients with diffuse large B-cell lymphoma. Cancer. 2016;122(20):3145-51.

27. Wist E, Risberg T. Trofosfamide in non-Hodgkin's lymphoma. A phase II study. Acta Oncol. 1991;30(7):819-21.

28. Salminen $\mathrm{E}$, Nikkanen $\mathrm{V}$, Lindholm L. Palliative chemotherapy in nonHodgkin's lymphoma. Oncology. 1997;54(2):108-11.

29. Helsing MD. Trofosfamide as a salvage treatment with low toxicity in malignant lymphoma. A phase II study. Eur J Cancer. 1997;33(3):500-2. 
30. Wiedemann GJ, Zschaber R, Hegewisch-Becker S, Reichardt P, Weber K, Uthgenannt $D$, et al. Two oral trofosfamide schedules in elderly patients with refractory non-Hodgkin's lymphoma. Onkologie. 1999;22:134-8.

31. Andersson PO, Braide I, Nilsson-Ehle H. Trofosfamide as a salvage therapy for anaplastic large cell lymphoma relapsing after high dose chemotherapy. Leuk Lymphoma. 2002:43:2351-3.

32. Hart C, Vogelhuber M, Wolff D, Klobuch S, Ghibelli L, Foell J, et al. Anakoinosis: communicative reprogramming of tumor systems - for rescuing from chemorefractory neoplasia. Cancer Microenviron. 2015;8(2):75-92.

33. Aigner B, Richtig E, Becker JC, Lingitz H, Marterer R, Niederkorn A, et al. Partial response of metastatic mucosal melanoma after palliative chemotherapy with trofosfamide: a case report. J Clin Oncol. 2013;31(2):e31-2.

34. Brinker A, Kisro J, Letsch C, Brüggemann SK, Wagner T, et al. New insights into the pharmacokinetics of trofosfamide. Int J Clin Pharmacol Ther. 2002; 40:376-81.

35. Lindemann $\mathrm{H}$, Harbers E. Interaction of three alkylating drugs, cyclophosphamide, ifosfamide and trofosfamide with DNA and DNAconstituents in vitro. Arzneimittelforschung. 1980;30:2075-80.

36. Klink T, Marxsen JH, Wagner T. Trofosfamide equally inhibits endothelial and tumor cell growth. Onkologie. 2002;25(Suppl 4):24 (A85).

37. Hempel G, Krumpelmann S, May-Manske A, Hohenlöchter B, Blaschke G, Jürgens $\mathrm{H}$, et al. Pharmacokinetics of trofosfamide and its dechloroethylmetabolites. Cancer Chemother Pharmacol. 1997;40:45-50.

38. Latz D, Nassar N, Frank R. Trofosfamide in the palliative treatment of cancer: a review of the literature. Onkologie. 2004;27:572-6.

39. Swerdlow SH, Campo E, Pileri SA, Harris NL, Stein H, Siebert R, et al. The 2016 revision of the World Health Organization classification of lymphoid neoplasms. Blood. 2016;127(20):2375-90.

40. A predictive model for aggressive non-Hodgkin's lymphoma. The international non-Hodgkin's lymphoma prognostic factors project. N Engl J Med. 1993;329:987-94.

41. Carbone PP, Kaplan HS, Musshoff K, Smithers DW, Tubiana M, et al. Report of the committee on Hodgkin's disease staging classification. Cancer Res. 1971;31:1860-1.

42. Cheson BD, Pfistner B, Juweid ME, Gascoyne RD, Specht L, Horning SJ, et al. Revised response criteria for malignant lymphoma. J Clin Oncol. 2007;25: 579-86.

43. Oken MM, Creech RH, Tormey DC, Horton J, Davis TE, McFadden ET, et al. Toxicity and response criteria of the eastern cooperative oncology group. Am J Clin Oncol. 1982;5:649-55.

44. Hoelzer D, Ludwig WD, Thiel E, Gassmann W, Löffler H, Fonatsch C, et al. Improved outcome in adult B-cell acute lymphoblastic leukemia. Blood. 1996;87(2):495-508.

45. Chiappella A, Castellino A, Nicolosi M, Santambrogio E, Vitolo U. Diffuse large B-cell lymphoma in the elderly: standard treatment and new perspectives. Expert Rev Hematol. 2017;10(4):289-97.

46. Laribi K, Denizon N, Bolle D. R-CVP regimen is active in frail elderly patients aged 80 or over with diffuse large B cell lymphoma. Ann Hematol. 2016; 95(10):1705-14.

47. Park SI, Grover NS, Olajide O, Asch AS, Wall JG, Richards KL, et al. A phase II trial of bendamustine in combination with rituximab in older patients with previously untreated diffuse large B-cell lymphoma. Br J Haematol. 2016; 175(2):281-9.

48. Weidmann E, Neumann A, Fauth F, Atmaca A, Al-Batran SE, Pauligk C, et al. Phase II study of bendamustine in combination with rituximab as first-line treatment in patients 80 years or older with aggressive B-cell lymphomas. Ann Oncol. 2011;22:1839-44.

49. Walter E, Schmitt T, Dietrich S, Ho A, Witzens-Harig M. Rituximab and bendamustine in patients with $\mathrm{CD}_{2} \mathrm{O}^{+}$diffuse large B-cell lymphoma not eligible for cyclophosphamide, doxorubicin, vincristine and prednisone-like chemotherapy. Leuk Lymphoma. 2012;53:2290-2.

Ready to submit your research? Choose BMC and benefit from:

- fast, convenient online submission

- thorough peer review by experienced researchers in your field

- rapid publication on acceptance

- support for research data, including large and complex data types

- gold Open Access which fosters wider collaboration and increased citations

- maximum visibility for your research: over $100 \mathrm{M}$ website views per year

At BMC, research is always in progress.

Learn more biomedcentral.com/submissions 